\title{
Participatory Promotion of Improved Chickpea Varieties in Habro and Oda Bultum Districts of West Hararghe Zone
}

\author{
Fekede Gemechu Asfaw Zewdu, \\ Mechara Agricultural Research Center, West Hararghe Zone
}

\begin{abstract}
This activity was conducted during the 2013 main cropping season at Habro and Oda Bultum districts of West Hararghe Zone to evaluate the performance of improved chickpea variety on farmer's field and strengthen stakeholder's linkage in the study area. A total of seventy (70) farmers from both district were participated for the activity. Three improved variety of chickpea (Minjar, Natoli and Habru) were evaluated with local checked to create awareness for farmers. 0.125 of land were used for each variety on each farmer's field. The result of the study showed that Minjar variety performed well than other improved varieties and local check in terms of yield from the same area on farmer's field. In addition, farmers also prefer Minjar variety in terms of its seed quality, seed size, early maturity and disease resistance over other improved varieties and local check. So, concerning body should scale up further for similar agro ecology to improve chickpea production and productivity of farming community.
\end{abstract}

DOI: $10.7176 / \mathrm{JNSR} / 11-17-06$

Publication date:September $30^{\text {th }} 2020$

\section{INTRODUCTION}

Agriculture is the fundamental driver for Ethiopia's economy and long-term food security as it offers about 80$85 \%$ of employment, more than $61 \%$ of the total export and $38.5 \%$ of gross domestic product of the country (Jima $\&$ Birhan 2017). Ethiopia has diverse agro-ecology that permits different agricultural systems and production of different crops. diverse agro-ecology together with diverse farming systems, socio-economic, cultures and climate zones provided Ethiopia with various biological wealth of plants, animals, and microbial species, especially crop diversity (Atnaf et al., 2015).

Legumes constitute a critical component of the agricultural system in Ethiopia; about 12 legume crops are grown in the country. Of these, faba bean (Vicia faba L.), field pea (Pisum sativum L.), chickpea (Cicer arietinum L.), lentil (Lens cultinaris Medik.), grass pea (Lathyrus sativus L.), fenugreek (Trigonella foenum-graecum L.) and lupine (Lupinus albus L.) are categorized as highland legume crops and grown in the cooler highlands. On the other hand, haricot bean (Phaseolus vulgaris L.), soya bean (Glycine max L.), cowpea (Vigna unguiculata L.), pigeon pea (Cajanus cajan L.) and mung beans (Vigna radiata L.) are categorized as lowland legume crops and predominantly grown in the warmer and low land parts of Ethiopia (CSA, 2018 \& Getachew, 2019).

Chickpea is one of the major pulses grown in Ethiopia, mainly by subsistence farmers usually under rain fed conditions. It is one of the main annual crops in Ethiopia both in terms of its share of the total cropped pulse area and its role in direct human consumption. It is grown widely across the highlands and semi-arid regions of the country (Bejiga et al. 1996). Chickpea is the most important pulse crop in Ethiopia, where the whole seeds are eaten fresh, cooked or boiled or in the form of dhal which is prepared by splitting the seed in a mill and separating the husk. Floor made by grinding the seed is one of the chief ingredients of everyday diet for those suffering from Uric Acid problem. The dry stems and leaves and husk after threshing are feed to livestock.

Two types of chickpea, Kabuli and Desi, are currently produced in Ethiopia. Kabuli or garbanzo type is usually large seeded with seed size ranging from $6-8 \mathrm{~mm}$ and smooth cream white seed coat colour. The production of Kabuli types is currently limited to few pockets, primarily in Eastern Shewa region where access to improved varieties has been promoted through better linkages with the research and extension system. Desi type chickpea, traditionally widely grown in the country, is small seeded with seed size ranging from 3-6 mm, and hard and reddish-brown colored seed coat (Bekele Sh. \& Hailemariam T., 2007).

Yields of chickpeas in the majority of traditional smallholding farms very low due to lack of improved technology concerning the crop.. However, many improved varieties of chickpea like Minjar, Natoli, Habru \& others) were developed by Ethiopian Agricultural Research Institute (EARI) which improves its productivity and production. Therefore, this activity was developed to evaluate those improved varieties of chickpea on farmer's field to improve their productivity and create awareness among different stockholders.

\section{METHODS AND MATERIALS}

Description of the Area

The activity was conducted in Habro and Oda Bultum districts of west Hararghe zone. Habro and Oda Bultum districts were located at $404 \mathrm{~km}$ and $362 \mathrm{~km}$ from Addis Abeba, respectively. Those two districts were known for chickpea production relative to other districts of west Hararghe zone. Specifically the activity was undertaken in 
four Peasant Associations of which Bareda, Abdi Gudina \& Haro Chercher from Habro district and Kara from Oda Bultum district. Generally, agro ecologies of the two districts were summarized as follows.

Table 1: Summery of Habro and Oda Bultum Agro-ecologies

\begin{tabular}{|l|l|l|l|l|l|l|l|}
\hline \multirow{3}{*}{ Name of the district } & \multicolumn{9}{|c|}{ Agro-ecology } \\
\cline { 2 - 7 } & \multicolumn{2}{|c|}{ Altitude(m.a.s.l) } & Temperature $\left({ }^{0} \mathrm{c}\right)$ & \multicolumn{2}{|c|}{ Rainfall(mm) } & \multirow{2}{*}{ Soil Type } \\
\cline { 2 - 7 } & Min. & Max. & Min. & Max. & Min. & Max. & Soil \\
\hline Habro & 1600 & 2400 & 16 & 20 & 650 & 1000 & Black sandy \& loam soil \\
\hline Oda Bultum & 1040 & 2500 & 25 & 28 & 900 & 1100 & Dominant in loam \& clay soil \\
\hline
\end{tabular}

Source: Farming System Study of Habro (Aman T. \& Anteneh T., 2001) \& Oda Bultum (Aman T. Anteneh T. \& Fekede G., 2001)

\section{Site and Experimental Farmers Selection Criteria}

Communication with district Agricultural Office (AO) and expert has been conducted to make the activity more participatory and select appropriate Kebele for Chickpea production in the study area.

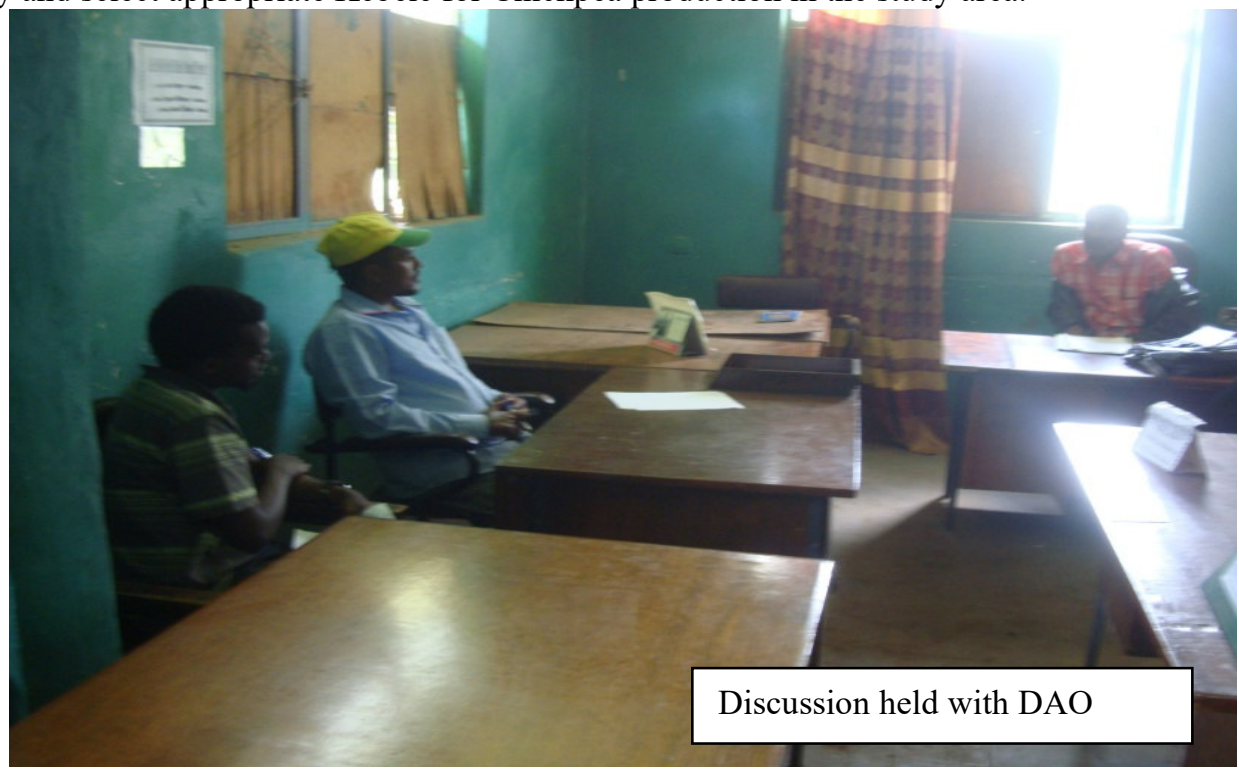

Accordingly, Bareda, Abdi Guddina, Haro Chercher and Kara Kebeles were selected based their potential production of chickpea in relation to other kebeles. Additionally, discussions were held with respective kebele officials and DAs to select farmers on which the activity conducted. These criteria includes: Farmers interest to the crop, model farmers, accessible of site, ability to risk taker, farmers who afford two timed of land for this experiment, farmers who manage their field on time( land preparation, sowing, weeding, harvesting, threshing) and others. Accordingly, a total of seventy (70) farmers were selected to conduct the activity.

Table 2: Summary of selected Kebele, farmers and area covered by improved crop

\begin{tabular}{|l|l|l|c|c|}
\hline No. & district & Kebele/PAs & $\begin{array}{l}\text { No. of Fs } \\
\text { participated }\end{array}$ & $\begin{array}{l}\text { Area of land covered by improved varieties in } \\
\text { Hec }\end{array}$ \\
\hline \multirow{3}{*}{1} & Habro & Haro Chercher & 19 & 2.4 \\
\cline { 2 - 5 } & & Bareda & 17 & 2.2 \\
\cline { 2 - 5 } & Abdi Guddina & 18 & 2.3 \\
\hline 2 & Oda Bultum & Kara & 16 & 2 \\
\hline \multicolumn{2}{|l}{ Total } & $\mathbf{7 0}$ & $\mathbf{8 . 9}$ \\
\hline
\end{tabular}

\section{Methods of Data Collection and Analysis}

Different data like yield data and farmers selection criteria were collect through supervision on prepared data collection sheet by researchers and DA of the PA. Organizing field day was also another way to collect farmer's attitude toward provided technology in relation to their agro ecology. The collected data (quantitative data) was analyzed by using average and frequency distribution while qualitative data were analyzed through qualitative interpretation.

\section{RESULT AND DISCUSSION}

Performances of improved chickpea varieties under Farmer's Condition

Habro and Oda Bultum districts were potential chickpea producing from west Hararghe Zone. Because of this 
three improved varieties of chickpea was compared with local variety on selected farmers to improve its production and productivity. Therefore, the performances of each variety were evaluated based on different parameter like yield data, farmers selection criteria by comparing each verity with local check. Table 4 showed that yield summery of each variety (Minjar, Natoli, Habru and local check) on farmers' circumstance and total field harvested from activity. The result indicated that the average yield of Minjar, Natoli, Habru and local check variety is 38.7, 43.2, 37.4 and 25.2 kuntal per hectare, respectively. From this we concluded that Natoli have yield advantage over other improved variety and local check.

Table 3: Summery of yield performance of the varieties per hectare

\begin{tabular}{|l|l|c|c|c|c|}
\hline No. & $\begin{array}{l}\text { Variety } \\
\text { Name }\end{array}$ & $\begin{array}{l}\text { Total area planted in } \\
\text { hectare }\end{array}$ & $\begin{array}{l}\text { Average yield per } \\
\text { hectare }\end{array}$ & $\begin{array}{l}\text { No. Fs } \\
\text { participated }\end{array}$ & Total yield harvested \\
\hline 1 & Minjar & 3.4 & 38.7 & 27 & 131.6 \\
\hline 2 & Natoli & 1.4 & 43.2 & 11 & 60.5 \\
\hline 3 & Habru & 4 & 37.4 & 32 & 149.6 \\
\hline 4 & Local & 8.8 & 25.2 & 70 & 221.76 \\
\hline
\end{tabular}

Source: Our Computation, 2014.

The above table indicated that a total of 341.7 kuntal yield were harvested from three improved varieties of chickpea provided for seventy farmers in the study area. This indicates that improved varieties of these three improved verity of chickpea were disseminated in the study area.

Photo: Performance of chickpea varieties on farmer's field

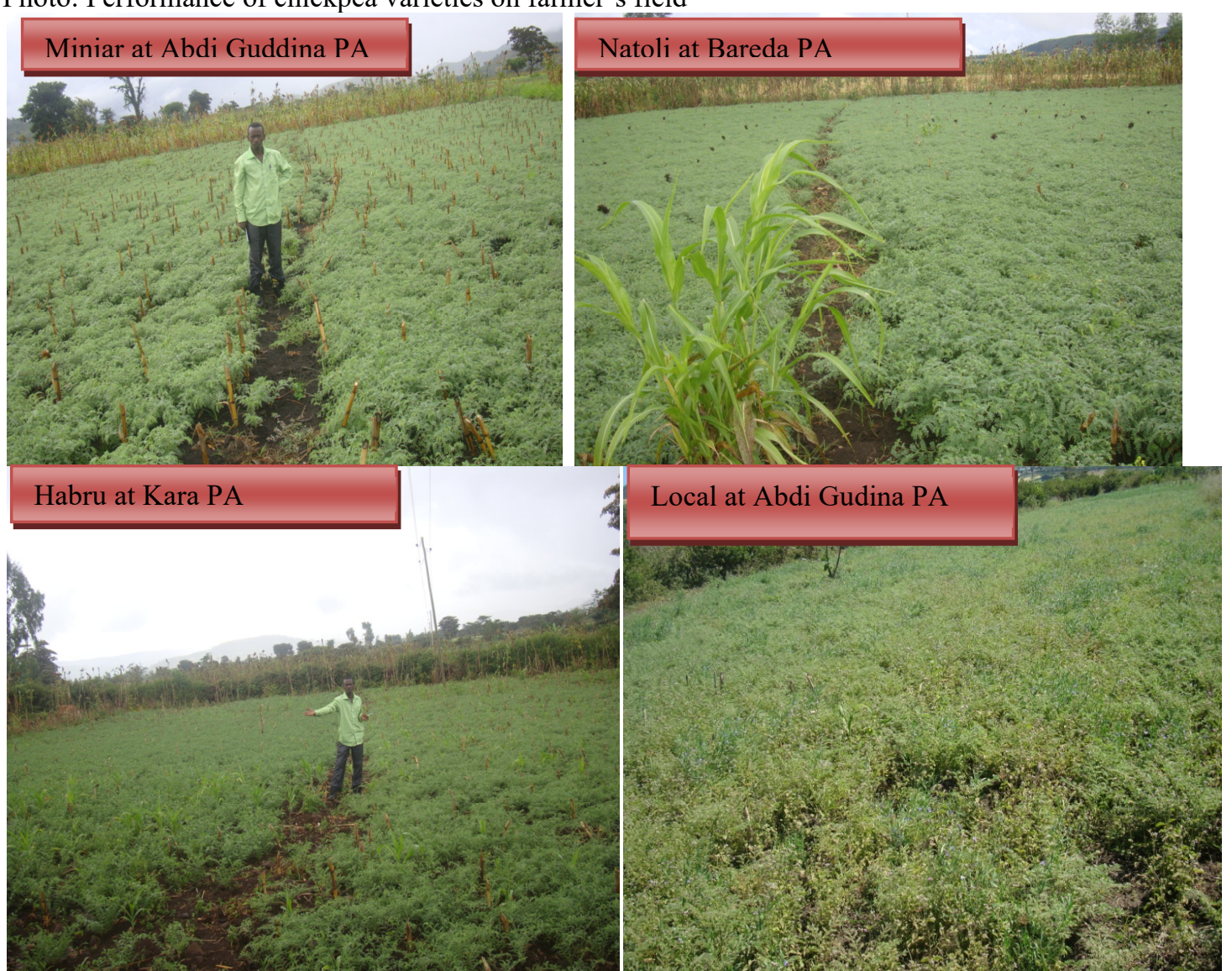

\section{Awareness Creation \& Capacity Building on Chickpea Production in the study area}

Additionally, farmer's field day was organized to facilitate experience sharing among farmers to get feedback and promote the technology to other stakeholders. Accordingly, participant of field day compared each variety with local and preferred Minjar variety due to its seed quality, seed size, early maturity and disease resistance over other improved varieties and local check. However, Natoli variety have yield advantage over other improved varieties and local check. 

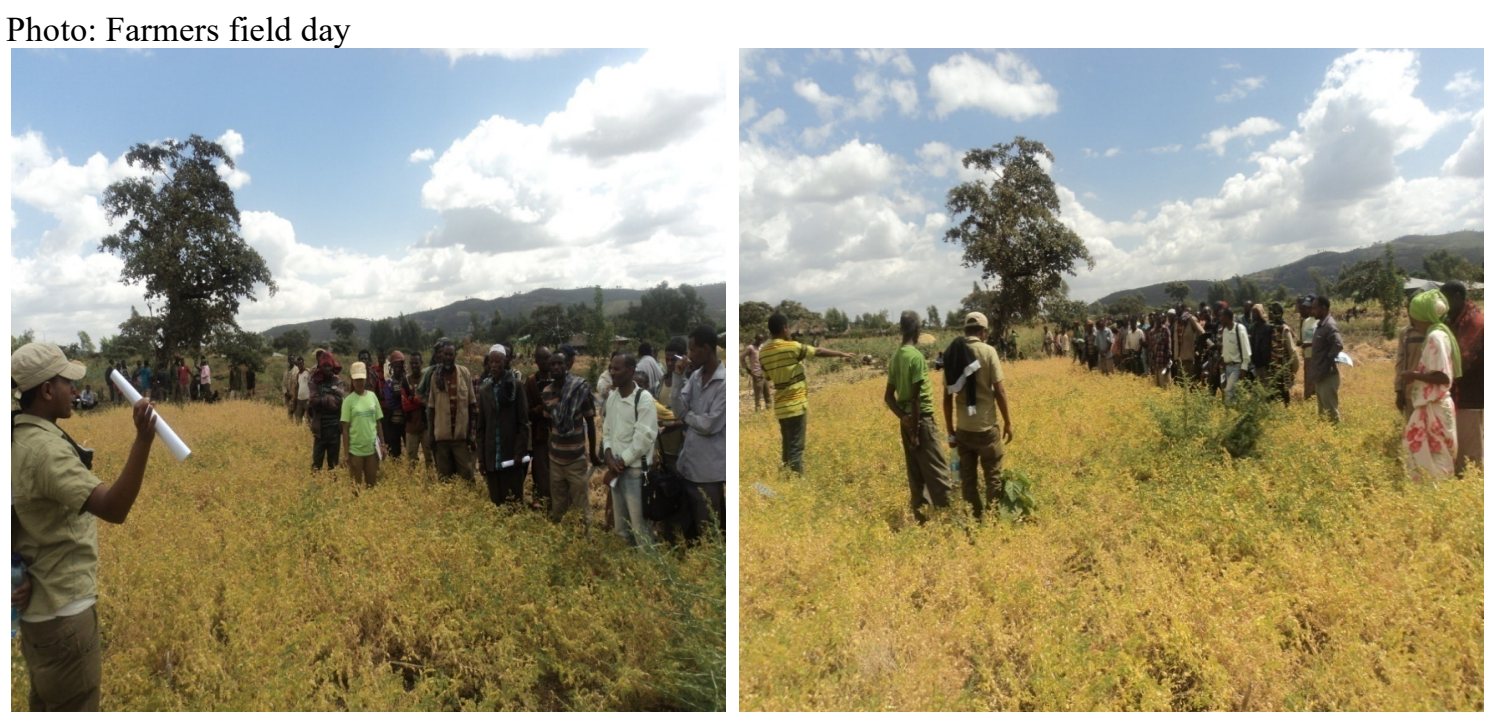

Training was provided for farmers and expert of agricultural offices to enhance their skill \& knowledge on chickpea production and management.

Table 4: Training participant on chickpea production and management

\begin{tabular}{|l|l|c|c|c|}
\hline \multirow{2}{*}{ No. } & \multirow{2}{*}{ Type of participant } & \multicolumn{2}{|c|}{ No. of participant } & \multirow{2}{*}{ Total participants } \\
\cline { 3 - 4 } & & Male & Female & \\
\hline 1 & Farmers & 29 & 3 & 32 \\
\hline 2 & Developmental agents & 6 & 2 & 8 \\
\hline 3 & Experts & 1 & 1 & 2 \\
\hline \multicolumn{2}{|l}{ Over all total } & $\mathbf{3 6}$ & $\mathbf{6}$ & $\mathbf{4 2}$ \\
\hline
\end{tabular}

Photo: Training provided to farmers
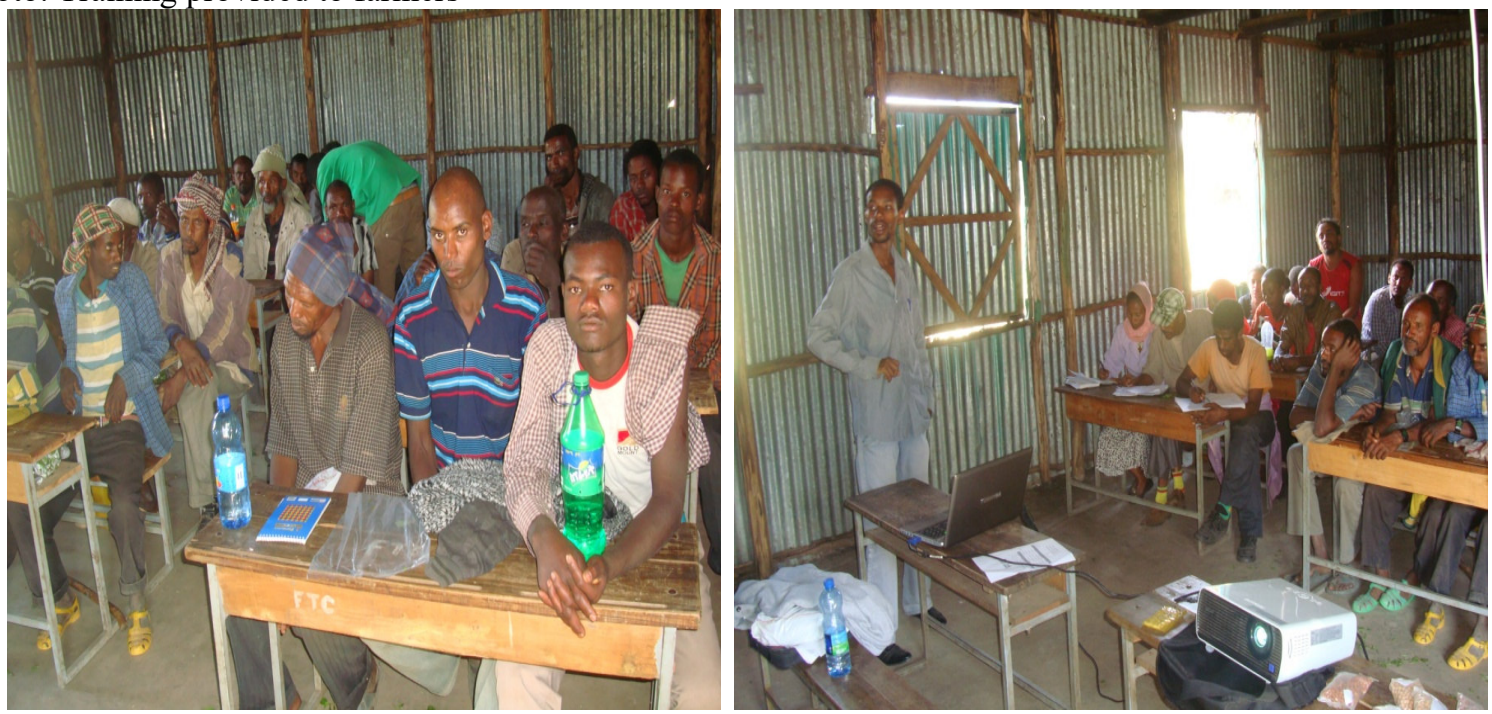

CONCLUSION AND RECOMMENDATION

Chickpea is legume crop grown for food and market purpose in West Hararghe Zone. Chickpea production play greater role in ensuring household food security in the study area. Due to this the activity was conducted in order to evaluate improved chickpea varieties on farmer's field. Accordingly, Minjar variety was selected by farmers for further dissemination due to its seed quality, seed size, early maturity and disease resistance over other improved varieties and local check.. Therefore, concerning body should give attention for further popularization in similar agro ecology with package of recommendation.

\section{REFERENCE}

Atnaf, M., Tesfaye, K., \& Dagne, K. (2015). The importance of legumes in the Ethiopian farming system and overall economy: An overview. American Journal of Experimental Agriculture, AJEA/2015/11253. 
Bejiga G, Eshetu M and Anbessa Y. 1996. Improved cultivars and production technology of chickpea in Ethiopia. Debre Zeit Agricultural Research Center (DZARC), Debre Zeit, Ethiopia.

Bekele Shiferaw and Hailemariam Teklewold. 2007. Structure and functioning of chickpea markets in Ethiopia: Evidence based on analyses of value chains linking smallholders and markets. Improving Productivity and Market Success (IPMS) of Ethiopian Farmers Project Working Paper 6. ILRI (International Livestock Research Institute), Nairobi, Kenya. 63 pp.

CSA (Central Statistical Agency). (2018). Agricultural sample survey, area and production of major crops (Private Peasant Holdings, Meher Season). Addis Ababa, Ethiopia.

Gaur PM, Tripathi S, Gowda CLL, Ranga Rao GV, Sharma HC, Pande S and Sharma M. 2010. Chickpea Seed Production Manual. Patancheru 502 324, Andhra Pradesh, India: International Crops Research Institute for the Semi-Arid Tropics. 28 pp.

Getachew, T. (2019). Pulse crops production opportunities, challenges and its value chain in Ethiopia: A review article. Journal of Environment and Earth Science, 9, 1. doi:10.7176/JEES

Jimma D., \& Birhanu. A., (2017). Assessment of Indigenous knowledge of smallholder farmers on intercropping practices in West Hararghe Zone; Oromia National Regional State, Ethiopia. Journal of Agricultural Economics and Rural Development, 3(3), 270-278. 